\title{
End of Paediatric Posting Assessment of Medical Interns at a Teaching hospital from Coastal Karnataka
}

\author{
Sahana KS', Qadiri GJ2', Saldanha PRM³
}

\begin{abstract}
Introduction: Internship is very a critical period of a medical undergraduate education during which student evolves into a doctor. The objectives of this study were to assess the interns at the end of their paediatric postings. Materials and Methods. Interns knowledge and skills were assessed at the end of their postings in the must know areas. Assessment was conducted by the trained faculty and interns were given the orientation about it. Method of assessment included OSCE, simulation based using standardized patients and computer based model driven simulators.Feedback was given to the students immediately at the end of their exam Results: Total 202 interns participated in the exam over the period of two years. New-borns assessment was done more frequently $(22.7 \%)$ and interpretation of investigations was less frequently assessed (7.9\%). Rest of other stations was assessed almost at the equal proportion. Highest score was observed in vaccines section (7.5) and lowest score was seen in procedures assessment (5.5). Conclusion. Interns were found to be weaker in procedural, communication and clinical scenario judgement skills which will help us in planning future training of the Interns.
\end{abstract}

Key words: Clinical rotatory internship, paediatrics, assessment

\section{Introduction}

$\mathrm{M}$ edical internship is the period where students are expected to learn additional skills, recognize emergency situations and enable them to become practice as primary care doctors. But there is a gradual decline in the overall competency level of interns ${ }^{1}$.

Given the vast diversity of medical institutions in the country offering medical education of variable standards, one common exam national exit exam (NEXT) is being proposed for undergraduates, which is opined to bring the quality and maintain the standard ${ }^{2}$. Though the guidelines are not very clear yet, the practical component is being planned to conduct after the internship which can significantly change the outlook towards practical learning during internship.

In our institute we initiated the clinical skill assessment examinations for interns to encourage them to learn the essential
${ }^{1}$ Dr. Sahana KS, MBBS. MD. Associate Professor, Department of Paediatrics, ${ }^{2} \mathrm{Dr}$. Ghulam Jeelani Qadiri, MBBS. MD. PhD, Fellow AHA (India), Dean, ${ }^{3} \mathrm{Dr}$. Prakash RM Saldanha MBBS. MD, Professor and HOD, Department of Paediatrics. All affiliated to Yenepoya Medical College, Deralakatte, Managalore, Karanataka, India.

\section{Address for correspondence}

Dr. Sahana KS, Associate Professor, Department of Paediatrics,

Yenepoya Medical College. Deralakatte, Managalore, Karanataka. India.

Tel No; +919986287218

E-mail; drkssahana@gmail.com

Acknowledgements: We would like to acknowledge Dr. Rashmi Jain, MBBS, MS, Associate Professor (Department of Ophthalmology) and MEU Co-ordinator, Yenepoya medical college for her assistance in editing the manuscript.

Funding: Nil

Conflict of Interest: None

Permission from IRB: Yes

\section{How to cite}

Sahana KS, Qadiri GJ, Saldanha PRM. End of Paediatric Posting Assessment of Medical Interns at a Teaching hospital from Coastal Karnataka. J Nepal Paediatr Soc 2018;38(2):90-93.

doi: http://dx.doi.org/10.3126/jnps.v38i2.19586

This work is licensed under a Creative Commons Attribution 3.0 License.

\section{(c) (i)}


clinical skills including communication and procedural skills along with the knowledge component during the internship period. Though there are many studies focusing on improvement of clinical competencies, at the post graduate trainee levels in paediatrics ${ }^{3}$ limited literature is available on effective internship learning and assessment. So this study is being undertaken to know the performance of interns in the must know areas at the end of their postings.

\section{Material and Methods}

This was a Cross sectional study. Clinical skill assessment exam was started for interns in our Institute of Yenepoya Medical College affiliated to Yenepoya deemed to be University as per the norms of our university from April 2015. At the end of the paediatric posting, that is at the end of one month, interns were assessed for their skills and knowledge. Students were given prior information regarding the date of examination. Interns were given orientation in the beginning of the postings about the essential skills and the basic knowledge that they are supposed to learn during their rotation. Method of assessment included OSCE, simulation based using standardized patients and computer based model driven simulators ${ }^{4}$. Even the faculty were trained for the OSCE exam through basic medical education workshop and through separate training sessions for simulation lab usage. The MEU members and subject experts (by the senior faculties within the department) performed design and content validation of the stations. Examination stations with the structured check lists were designed by the one person who was in charge of the intern's clinical skill assessment examinations and the other faculty were briefed about it for the objective assessments. It was both a formative and summative assessment which was done both at the end of the paediatric postings and at the end of their internship. Students were given the extension if they failed in the assessment.

The skills assessed for Interns were as per the recommendations of the $\mathrm{MCl}$ regulations for graduate medical education ${ }^{5}$. These included:-New-born Resuscitation, Paediatric Emergency (Case Scenario), Vaccine administration, Drug Administration, Common diagnostic/therapeutic Procedures, Interpretation of Common Investigations, Clinical examination skills and Communication skills.

The procedures assessed included nebulisation, insertion of naso-gastric tube, Monteux test. Skills and knowledge related to method of administration, storage and common side effects of certain vaccines like BCG, Hepatitis B, OPV, IPV, DPT and MMR were assessed.
Similar line of assessment was done for commonly used drugs like adrenaline, paracetamol, ORS, frusemide and certain antibiotics for their dose, route and use in the paediatric clinical scenarios.

Clinical scenarios included the assessment of dehydration, shock and its management, calculation of maintenance IV fluids, snake bite and identification of SAM. Due to the availability of simulation lab, it was easy for us to mimic the scenarios.

Examination skills included blood pressure measurement, systemic examination and anthropometric measurements. Counselling skills included counselling the mother with febrile seizures child, breast feeding and counselling the mother for phototherapy. New-born stations concentrated on basic new-born care, neonatal resuscitation and assessment and management of common neonatal problems

Feedback was given to the students immediately at the end of their assessment. Feedback was taken from the faculty members based on 5 point Likert scale (level of agreement). The data was entered in the excel sheet and analysed with SPSS software version 22. Approval from the institutional ethical committee was obtained which granted us the waiver of informed consent from the study participants.

\section{Results}

Total 202 interns participated in the exit exam. It was started in the year April 2015 and continued for more than of two years till date. Those interns who could not attend on the date were given rescheduled date.

Duration of the each session was about $5 \mathrm{~min}$. Table 1 gives the details of the assessment.

Table 1: Details of the Examinations ( $n=202)$

\begin{tabular}{lc}
\hline Focus area assessed & Number (percentage) \\
\hline Vaccines & $24(11.8 \%)$ \\
\hline Drugs & $21(10.3 \%)$ \\
\hline Communication skills & $25(12.3 \%)$ \\
\hline Procedures & $24(11.8 \%)$ \\
\hline Examination skills & $21(10.3 \%)$ \\
\hline Clinical scenarios and & $25(12.3 \%)$ \\
judgement & $46(22.7 \%)$ \\
Newborn & $16(7.9 \%)$ \\
\hline Investigations &
\end{tabular}

New-borns section was assessed maximum and interpretation of investigations was less frequently assessed. Rest of other stations were assessed almost at the equal proportion. 
Table 2: Details of Scoring in Exit Exam (Out Of 10)

\begin{tabular}{lcc}
\hline Focus Area & Mean Score & Range \\
\hline Vaccines & 7.5 & $4-10$ \\
\hline Drugs & 6.25 & $3-10$ \\
\hline Communication skills & 6 & $2-9$ \\
\hline Procedures & 5.5 & $2-9$ \\
\hline Examination skill & 7 & $5-10$ \\
\hline Clinical scenarios and & 6 & $1-10$ \\
judgement & 6.5 & $2-9$ \\
\hline New born & 6.5 & $3.5-8$ \\
\hline Investigations & &
\end{tabular}

Highest score was observed in vaccines section and lowest score was seen in procedures assessment.

Feedback was taken from all the faculty members regarding clinical posting assessment of interns and the details are given below (Table 3 ). Overall agreement percentage observed was $74.9 \%$ (score 4 or above on 5 point likert scale on level of agreement). Highest level of agreement was seen for the assessment of communication skills which was found to be satisfactory.

Table 3: Feedback taken from the faculty regarding the end posting evaluation of interns $(n=9)$

\begin{tabular}{lc}
\hline Feedback & Agree (\%) \\
\hline $\begin{array}{l}\text { Assessment should be done for all the } \\
\text { interns. Compulsory }\end{array}$ & $77.7 \%$ \\
\hline $\begin{array}{l}\text { This exam is helping them to improve } \\
\text { their knowledge and skills. }\end{array}$ & $66.6 \%$ \\
\hline $\begin{array}{l}\text { Conduction of exam was smooth } \\
\text { Communication skills assessment is } \\
\text { satisfactory. }\end{array}$ & $66.6 \%$ \\
\hline
\end{tabular}

\section{Discussion}

Research continues to document serious deficiencies in clinical skill among students and interns of medical colleges. Traditionally log book recording and monitoring has been used as tool but level of scrutiny varies. Newer methods of assessment have been developed focusing on various skills among which we used OSCE and simulation based assessment. Objective Structured Clinical Examinations (OSCEs) have been used by medical schools as it is a precise, objective, and reproducible allowing uniform testing of students for a wide range of clinical skill ${ }^{6}$.

Study done by Short et al, on 106 interns where they found out that OSCE exam resulted in statistically significant improvement in all core competencies like patient care, medical knowledge, practice-based learning and improvement, interpersonal and communication skills, professionalism, and systems-based practice ${ }^{7}$.
In our study $66.6 \%$ of our faculty agreed that clinical assessment is helping them to improve their knowledge and skills.

In a study done by Ben et al, noted that the implementation of the modified-OSCEs at their institution has been one of the tools responsible for paediatrics residents performance improvement and students also stated that experiences was very much educational ${ }^{8}$ though in our study feedback from the students was not taken.

Pelly et al identified the important gaps in the knowledge and skills of graduating medical students in Canada regarding vaccines indications, contraindications, adverse events, safety and patient interaction ${ }^{9}$. But in our study highest scoring was observed in the vaccine section. Doing the reassessment regarding vaccination at the internship makes it obligatory for the students to learn the more practical and technical aspects like method of administration and storage.

In a study done Gloria et al, they opined that the feasibility of the continuous implementation of a system should be taken into account from the beginning of the project since the resources available such as human and material may be limited ${ }^{10}$. We also agree with the same as it requires lot of efforts and time to prepare the stations and coordination among faculty members.

In a study done by Sharma et al, it was found that almost $50 \%$ of the interns practiced and learned skills because of the assessment and whatever the interns practice or learns, the skill must be assessed based on their learning objectives as defined in the log book ${ }^{11}$.

Undergraduate medical education in India is lacking in doctor-patient communication skills ${ }^{12}$. So assessing the communication skill during internship will also help us to give them the constructive feedback and gives scope for improvement.

Different methods of assessment have also been used like Mini- clinical evaluation exercise (mini-CEX examination) by Balamurugan et al for interns and concluded that there is a lot of potential for improvement of students with respect to clinical skills ${ }^{13}$. Morris et. al., systematically reviewed the literature to identify and grade tools used for the end point assessment of procedural skills (e.g., phlebotomy, IV cannulation, suturing) competence in medical students prior to certification and they concluded that there is a need to develop standardized tools with proven reliability and validity for assessment of procedural skills competence at the end of medical training. Medicine graduates must 
have comparable levels of procedural skills acquisition entering the clinical workforce irrespective of the country of training ${ }^{14}$.

So, intern's examination at the end of their postings helped in skill orientation training during their postings and which in turn led to the improved performance of students in overall clinical care of the patients.

\section{Conclusion}

Interns were found to be weaker in procedural, communication and clinical scenario judgement skills which will help us in planning future training of the Interns.

9. Pelly LP, Macdougall DMP, Halperin BA, Strang RA, Bowles SK, Baxendale DM et al. THE VAXED PROJECT: An Assessment of Immunization Education in Canadian Health Professional Programs. BMC Med Educ 2010;10:86. DOI: 10.1186/1472-6920-10-86.

10. Sandoval GE, Valenzuela PE, Monge MM, Tos PA, Trivino XC, Wrigth AC, Paris E, Sánches I, Valdivia GS. Analysis of a learning assessment system for pediatric internship based upon objective structured clínical examination, clínical practice observation and written examination. J Pediatr (Rio J) 2010;86(2):131136. DOI: http://dx.doi.org/10.1590/S002175572010000200009

11. Sharma DB, Shah UM, Gupta V, Saxena K, Singh US. Skills assessment during internship: A novel approach to enhance competencies among Indian medical graduates. Natl J Physiol Pharm Pharmacol 2017;7(6):603-607. DOI: 10.5455/ njppp.2017.7.0202814022017

12. Singhal K, Ramakrishnan K. Training needs of international medical graduates seeking residency training: Evaluation of medical training in India and the United States. Internet J Fam Pract 2003;3(1):1-9. DOI: ispub.com/IJFP/3/1/8127.

13. Balamurugan PV, Jayapriya B, Geetha K, Jafrin L. Teaching and Assessment of Clinical Skills in Interns using the Mini Clinical Evaluation Exercise (Mini-CEX) in a South Indian Medical College - a Pilot Study. J Den Med Sci 2017;16(5):69-73. DOI: 10.9790/08531605096973

14. Morris MC, Gallagher TK, Ridgway PF. Tools used to assess medical student's competence in procedural skills at the end of a primary medical degree: a systematic review. Med Educ Online 2012;17:18398. DOI: http://dx.doi.org /10.3402/meo.v17io.18398. 